ISBN 978-93-84468-94-1

International Conference on Education, Business and Management (ICEBM-2017)

Bali (Indonesia) Jan. 8-9, 2017

\title{
Staff Efficiency Improvement of operations of Honda Manufacturing Co., Ltd. Thailand
}

\author{
Toru Sato, Suthum Phongsamran \\ Postgaduat school of business administration, Kasembundit University, Bangkok \\ planning@kbu.ac.th
}

\begin{abstract}
The purpose of this study is to determine the factors of employees' performance motivation in motorcycle engines assembly division, Thai Honda Manufacturing Co., Ltd. Findings from the study revealed that most of respondents were males, age less than 26 years old, operational staff, earned less than bachelor degree, and period of work less than 6 years.Recommendations from the study were that administrative officers should increase performance efficiency by building work motivation, adjusting salary and compensation to current cost of living expenses, assign special job to increase skill, two ways communication between staff and supervisors, create events and activities in order to build relationship among workers, job rotation, and assign job with responsibility that appropriate to skill level.
\end{abstract}

Keyword: Staff Efficiency Improvement

\section{Introduction}

The changing of today's world, the intensity of competition in various ways and the development of organization is necessary to increase the effectiveness and operational capability to accommodate the changes in world of competition. What executives should consider are new visualization on improving operational performance which will require an effective human resources management in order to achieve the goal with maximum efficiency that depend on the performance motivation of the employees which is an important component on enhancing performance efficiency of human resources. Therefore, human resources that already have knowledge and Capabilities of performing are still require to enhance performance motivation to increase efficiency by the employer as well.

Thai Honda Manufacturing Co., Ltd., established in 2508 BC., and relocated in Lad Krabang Industrial Estate in 2535 BC., and the registered capital amount 150 million baht, shareholders for Thai Honda Manufacturing Co., Ltd., of 60 percent, Thai shareholders which are Pornprapha family of 17 percent, other 23 percent. The company is a biggest motorcycle engines manufacturing company in the world with 8,387 employees (based on information, July 2558 BC), the total of productions are 26,540,000 motorcycles and 28,530,000 motorcycle engines and exported motorcycles to Japan, Asian countries, Brazil, and Europe (more than 71 countries around the world) and exported motorcycle engines to in Asia, Europe, America, and Brazil (more than 80 countries).

In the current situation, the motorcycle engines that exported to Japan received complaints regarding of engines failure, all issues were about the quality of engine which have troubled, and the reported of 138 issues about engines malfunction. All of this issue were related to nonstandard engines assembly which may had resulted from the work efficiency of employees. The work performance efficiency of employees reduced may came from the lack of motivation of the employer, all of this situation may cause the cost of doing business and customers turn away from the company because customer lack of confidence in the quality of the company productions. 
From introduction above, researcher are interested in studying staff Efficiency improvement of operations of Thai Honda Manufacturing Co., Ltd. and results from the study in strengthening the staff performance efficiency for Thai Honda Manufacturing Co., Ltd.

Two-factor theory and concepts of Frederick Herzberg's Two-Factor Theory

\section{Two-factor theory distinguishes between:}

1. Motivators (e.g. challenging work, recognition for one's achievement, responsibility, opportunity to do something meaningful, involvement in decision making, sense of importance to an organization) that give positive satisfaction, arising from intrinsic conditions of the job itself, such as recognition, achievement, or personal growth.

2. Hygiene factors (e.g. status, job security, salary, fringe benefits, work conditions, good pay, paid insurance, vacations) that do not give positive satisfaction or lead to higher motivation, though dissatisfaction results from their absence. The term "hygiene" is used in the sense that these are maintenance factors. These are extrinsic to the work itself, and include aspects such

as company policies, supervisory practices, or wages/salary. Herzberg often referred to hygiene factors as "KITA" factors, which is an acronym for "kick in the ass", the process of providing incentives or threat of punishment to make someone do something.

According to Herzberg, hygiene factors are what causes dissatisfaction among employees in a workplace. In order to remove dissatisfaction in a work environment, these hygiene factors must be eliminated. There are several ways that this can be done but some of the most important ways to decrease dissatisfaction would be to pay reasonable wages, ensure employees job security, and to create a positive culture in the workplace. Herzberg considered the following hygiene factors from highest to lowest importance: company policy, supervision, employee's relationship with their boss, work conditions, salary, and relationships with peers. Eliminating dissatisfaction is only one half of the task of the two factor theory. The other half would be to increase satisfaction in the workplace. This can be done by improving on motivating factors. Motivation factors are needed to motivate an employee to higher performance. Herzberg also further classified our actions and how and why we do them, for example, if you perform a work related action because you have to then that is classed as "movement", but if you perform a work related action because you want to then that is classed as "motivation". Herzberg thought it was important to eliminate job dissatisfaction before going onto creating conditions for job satisfaction because it would work against each other.

\section{The purpose of the study}

The purpose of this study is to determine the factors of employees' performance motivation in motorcycle engine assembly division, Thai Honda Manufacturing Co., Ltd.

\subsection{Research Methodology}

\section{Sample selection}

The samples were 134 employees in motorcycle engine assembly division, Thai Honda Manufacturing Co., Ltd.

\section{Data collection procedure}

The questionnaires were distributed to sample of 134 employees in motorcycle engine assembly division, Thai Honda Manufacturing Co., Ltd. A total of 134 usable questionnaires were returned back to the researcher, yielding a 100 percent response rate and no missing data.

TABLE: I: shows comparison of personal different between gender and employees' performance motivation in motorcycle engine assembly division, Thai Honda Manufacturing Co., Ltd.

\begin{tabular}{|c|c|c|c|c|c|}
\hline Gender & Mean & S.D. & t & df & Sig. \\
\hline Male & 3.57 & 0.179 & -0.433 & 132 & 0.564 \\
\hline Female & 3.64 & 0.181 & & & \\
\hline
\end{tabular}

*Significant level 0.05 
From table 1: the test of hypothesis revealed that value of t-test was at significant level 0.05 founded that work performance with value of significant at 0.564 which was higher than value of significant level 0.05 , accepted main hypothesis HO meaning that personal different such as gender was not affected employees' performance motivation in engine assembly division, Thai Honda Manufacturing Co., Ltd.

TABLE: II: shows comparison of personal different between occupation position and employees' performance motivation in motorcycle engine assembly division, Thai Honda Manufacturing Co., Ltd.

\begin{tabular}{|c|c|c|c|c|c|}
\hline Position & Mean & S.D. & t & df & Sig. \\
\hline Staff & 3.55 & 0.394 & -2.421 & 132 & 0.170 \\
\hline Supervisor & 4.50 & 0.239 & & & \\
\hline
\end{tabular}

*Significant level 0.05

From table 2: the test of hypothesis revealed that value of t-test was at significant level 0.05 founded that work performance with value of significant at 0.170 which was higher than value of significant level 0.05 , accepted main hypothesis $\mathrm{H} 0$ meaning that personal different such as occupation position was not affected employees' performance motivation in engine assembly division, Thai Honda Manufacturing Co., Ltd.

TABLE III: shows comparison of personal different between age and employees' performance motivation in motorcycle engine assembly division, Thai Honda Manufacturing Co., Ltd.

\begin{tabular}{|c|c|c|c|c|c|}
\hline employees' performance motivation & SS & df. & MS & F & Sig. \\
\hline Between group & 0.242 & 3 & 0.081 & 0.086 & 0.968 \\
\hline Within group & 122.183 & 130 & 0.940 & & \\
\hline Total & 122.425 & 133 & & & \\
\hline
\end{tabular}

*Significant level 0.05

From table 3: the test of hypothesis revealed that value of one-way Anova was at significant level 0.05 founded that work performance with value of significant at 0.968 which was higher than value of significant level 0.05 , that accepted main hypothesis $\mathrm{H} 0$ meaning that personal different such as age was not affected employees' performance motivation in motorcycle engine assembly division, Thai Honda Manufacturing Co., Ltd.

TABLE IV: shows comparison of personal different between level of education and employees' performance motivation in motorcycle engine assembly division, Thai Honda Manufacturing Co., Ltd.

\begin{tabular}{|c|c|c|c|c|c|}
\hline employees' performance motivation & SS & df. & MS & F & Sig. \\
\hline Between group & 9.071 & 2 & 4.536 & 5.242 & 0.006 \\
\hline Within group & 113.354 & 131 & 0.865 & & \\
\hline Total & 122.425 & 133 & & & \\
\hline
\end{tabular}

*Significant level 0.05

From table 4: the test of hypothesis revealed that value of one-way Anova was at significant level 0.05 founded that work performance with value of significant at 0.006 which was less than value of significant level 0.05, that refused main hypothesis $\mathrm{H} 0$ meaning that personal different such as level of education affected employees' performance motivation in motorcycle engine assembly division, Thai Honda Manufacturing Co., Ltd.

Table 5: shows comparison of personal different between work period with company and employees' performance motivation in motorcycle engine assembly division, Thai Honda Manufacturing Co., Ltd.

\begin{tabular}{|c|c|c|c|c|c|}
\hline employees' performance motivation & SS & df. & MS & F & Sig. \\
\hline Between group & 2.850 & 3 & 0.950 & 1.033 & 0.380 \\
\hline Within group & 119.575 & 130 & 0.920 & & \\
\hline Total & 122.425 & 133 & & & \\
\hline
\end{tabular}

*Significant level 0.05

From table 5: the test of hypothesis revealed that value of one-way Anova was at significant level 0.05 founded that work performance with value of significant at 0.380 which was more than value of significant level 0.05 , that accepted main hypothesis $\mathrm{H} 0$ meaning that personal different such as work period with company was 
not affected employees' performance motivation in motorcycle engine assembly division, Thai Honda Manufacturing Co., Ltd.

\section{Summary of Study Results}

Findings from the study revealed that most of respondents were males, age less than 26 years old, operational staff, earned less than bachelor degree, and period of work less than 6 years.

\subsection{Suggestions for future research}

For the future study, researcher should study in more details from all level of employees in order to receive accurately results of analysis.

\section{References}

[1] Amornrat Chukeaw. (2555). Performance motivation of staff at Ummarit and Associate Co., Ltd., Master of Business Administration, Taksin University.

[2] Herzberg, Frederick (January-February 1968). "One More Time: How Do You Motivate Employees?" Harvard Business Review. 46 (1): 53-62. OCLC 219963337.

[3] "Herzberg's Motivation-Hygiene Theory (Two Factor Theory)". NetMBA.com. Retrieved December 9, 2014.

[4] Herzberg, Frederick; Mausner, Bernard; Snyderman, Barbara B. (1959). The Motivation to Work (2nd ed.). New York: John Wiley. ISBN 0471373893

[5] Hackman, J. Richard; Oldham, Greg R. (August 1976). "Motivation through the Design of Work: Test of a Theory". Organizational Behavior and Human Performance. 16 (2): 250-279. Doi: 10.1016/0030-5073(76)90016-7. OCLC 4925746330.

[6] Paiboon Tanjai. (2554). Work performance efficiency of employees. Graduate school, Chulalongkorn Ratchavitayalai Universitya.

[7] Pitchaya Vattanrangsan. (2558). Improvement performance efficiency of personnel at 4 stars Hotel, Siam square district, Master of Arts, Bangkok University.

[8] Nognnuch Promchan. (2552) Guideline of Improvement performance efficiency of personnel At Plaza Attini Royal Meridian, Master of Business Administration, Kasem Bundit University.

[9] Tosapon Apinyapanja. (2550). Factors affecting performance efficiency of personnel at Green World publication Co., Ltd., Master of Business Administration, Kasem Bundit University.

[10] Sivaporn Keawkoom. (2554). Factors affecting work performance of personnel at Siam Commercial Bank, Ratchamongkol Rattanakosin Technology University.

[11] Pravena Pulkate. (2552). Factors affecting production performance: case study, T Krung Thai Industrial Co., Ltd., Master of Business Administration, Kasem Bundit University.

[12] Prateep Yongrit. (2551). Guideline of building work motivation of employees at CPN Tran Service International Co., Ltd., Independent Study, Master of Business Administration, Kasem Bundit University.

[13] Parichat Yotsakorn. (2549). Guideline of health supplementary for work efficiency of staff At Mericom Imaging System Co., Ltd., Thailand, Independent Study, Master of Business Administration, Kasem Bundit University.

[14] Siriporn Noparat. (2551). Factors affecting work performance motivation of employees at NI Co., Ltd.,Thailand,

[15] Sukhothaitammatirat University.

[16] Tarintorn Suppakitkamjon. (2542). Work satisfaction of personnel at North-East College, Thesis, Khonkaen University. 